\title{
INTRODUCTION: TRADITIONS AND PERSPECTIVES \\ OF THE PHENOMENOLOGICAL MOVEMENT \\ IN CENTRAL AND EASTERN EUROPE
}

WITOLD PŁOTKA

The term "phenomenology» is equivocal, since it refers either to the philosophical tradition developed as the phenomenological movement that originates with cooperation of Edmund Husserl (1859-1938) with the Munich Circle, or to a specific method of doing philosophy that consists in describing given phenomena in their essences. Herbert Spiegelberg (Spiegelberg, 1975, 20) calls the latter form «first-hand phenomenology», because it is about the phenomena, and he contrasts it with studying of texts as texts that are elements of the phenomenological movement; if one investigates texts, however, he or she does not do - as Spiegelberg (Spiegelberg, 1975, 20-21) states - «phenomenology proper» but rather phenomenology «in a sense of meta-phenomenology». The present issue of the «Horizon. Studies in Phenomenology» can be regarded as an attempt to bridge the gap between the two meanings with regard to the phenomenological movement in Central and Eastern Europe. For this reason, the main aims of the issue are twofold: first, it is to present the context, central figures, trends, and periods of phenomenology in Central and Eastern Europe, and second, it is to show original contributions of philosophers from this part of Europe to contemporary debates in phenomenology. Why, however, this fragment of the phenomenological movement needs a special attention?

We can initially assume that a need to explore the issue rises from a recognition of a lack of this topic in the main historical works on phenomenology. Even though Spiegelberg (Spiegelberg, 1999), and the authors of the Encyclopedia of Phenomenology 
(Embree, 1997) refer to Central and Eastern Europe, and they list a series of names and titles, it often seems to be reductive, selective, and schematic. In the «Part Four» of The Phenomenological Movement. A Historical Introduction dedicated to the «Geography of the Phenomenological Movement», Spiegelberg (Spiegelberg, 1999, 666-667) devotes to Central and Eastern Europe five paragraphs that present a sketch, rather than even a short introduction to this topic. ${ }^{1}$ In turn, the Encyclopedia of Phenomenology presents a richer perspective, but also in this book one finds more black holes than one can expect. There are, of course, entries on «Czechoslovakia», «Hungary», «Poland», «Russia», «Union of Soviet Socialist Republics», and on «Yugoslavia», but there is no separate entry, e.g., on «Czech Republic», «Slovakia», «Romania», «Lithuania», or — what is more important — on «Central and Eastern Europe». In result, as it seems, one cannot understand a specific character of the phenomenological movement from this part of the world. So, the need to deepen our knowledge of the phenomenological movement in Central and Eastern Europe follows from a remarkable absence of this area in studies on phenomenology. But, is it justified at all to explore this aspect of the phenomenological heritage? And, what follows, does phenomenology in Central and Eastern Europe present any specific way of doing phenomenology?

Before answering these fundamental questions, however, it is worth to make a more general comment. After over 11 decades after Husserl's Logical Investigations, there is no common agreement on any criterion that enables a strict definition of what phenomenology is, namely, as a distinct and separate discipline or current in philosophy. Some researchers question any attempts to indicate such differentia specifica of phenomenology. Of course, such problems are not unique for phenomenology, but rather concern many, if not all, currents in philosophy. So, what is phenomenology? Maurice Merleau-Ponty (1908-1961) noticed in his Phenomenology of Perception that «It may seem strange that this question has still to be asked half a century after the first works of Husserl. The fact remains that it has by no means been answered.» (MerleauPonty, 2002, vii) As it is well known, to break the deadlock, Spiegelberg offered four

\footnotetext{
1 In the «Part Two» of his book, Spiegelberg refers also to Wilhelm Szilasi (1889-1966), Roman Ingarden (1893-1970), and Jan Patočka (1907-1977) as members of the Central and Eastern European movement, however, he indicates their involvement mainly in German philosophical tradition.
} 
possible criteria to define a philosopher as a member of a given movement. So, there are:

(1) the one-sided option of the self-declared members of such a movement; (2) the recognition by others, such as (a) the founder of the movement, (b) a representative group of insiders, and (c) a similar group of outsiders; (3) the historian's decision based on certain objective criteria in the thought of the thinkers in question (a solution particularly easy to apply where the label is posthumous, as is the case with most «isms» before the $18^{\text {th }}$ century); (4) any combination of the three preceding criteria. (Spiegelberg, 1999, 3)

For Spiegelberg phenomenology can be defined either «from the top down» or «from the bottom up». By the former, I understand an attempt to formulate a defined set of features or aspects that taken as a whole define phenomenology. Here, the criteria seem to be objective, however, they are exclusive of thinkers that cannot fit the definition. Therefore, the latter way of defining phenomenology that consists in including selfdeclared members, and members recognized by others seems to be more adequate. Such a definition formulated «from the bottom up» enables one to include different approaches to phenomenology. So, even though the presented criteria are problematic, the tools formulated by Spiegelberg seem to present a useful method to define what phenomenology is. Keeping this in mind, we can claim that phenomenology is irreducible to a defined set of features or aspects. Rather, phenomenology defines itself by a plurality of its members, descriptions, exchanges, discussions, polemics, and theories. In a word, the phenomenon of phenomenology is inseparable from the phenomenological movement. I think that this essential character of the phenomenological movement corresponds with Husserl's description of historical character of sciences in general, and of phenomenology in particular. If so, also phenomenology in Central and Eastern Europe is so-to-speak constituted by its history, and its horizon.

Indeed, the phenomenological movement in Central and Eastern Europe was defined by its historical situation and, even more importantly, by political circumstances. I do not claim that historical and political situation determined phenomenology, but I think it is one of the essential factors that characterizes the phenomenological movement in Central and Eastern Europe as a unique, and distinct way of doing phenomenology. Going one step further then one can claim that history of the phenomenological movement in this part of Europe is divided into at least three periods: (1) early phenomenology before the World War II, (2) confrontation of phenomenology with Marxism and communism after the World War II, and (3) contemporary phenomenology 
after 1989-1990, so after the fall of communism. It is hard to present even a sketch of every period since they seemed to be different in each country. Let me indicate only few aspects.

The phenomenological movement was established in Germany at the beginning of the XX century. Even though, early phenomenology in Central and Eastern Europe was shaped by German tradition (many of Central and Eastern European phenomenologists studied by Husserl, and collaborated, e.g., with the Munich Circle), it was shaped in a dialog by referring to specific topics present in certain regions. In result of this collaboration, a difficult German phenomenological vocabulary was translated into various national languages from Central and Eastern Europe. After the first period of reception of new phenomenological ideas, thinkers, writers, and even artists from Central and Eastern Europe established their own understanding of what phenomenology is, and they developed it in new directions crossing the theoretical borders defined by Husserl. A development of phenomenology was discontinued by the World War II, and a new political order of Europe. The Iron Curtain made impossible an international exchange of scholars, and ideas. Starting from 1945-1946, national borders have divided the phenomenological movement into a mosaic of theories. Nonetheless, it was limited to the theory only. Insofar as phenomenology was regarded as opposed to Marxism, and as such as idealism, and as a bourgeois philosophy, phenomenologists were regarded as enemies of the proletariat. In result, many phenomenologists have fallen victims to repressions. At the same time, phenomenology founded a resistance against materialism. According to Michael Gubser (Gubser, 2014), phenomenology founded also a resistance against communist regimes. So, the meaning of phenomenology in Central and Eastern Europe was shaped by political circumstances more - as it seems - than in other regions of the world.

Here, following Milan Kundera, we can remark that Central and Eastern Europe seems to have something in common, namely, its culture. In his famous essay on The Tragedy of Central Europe, Kundera notices that Central European countries defined their identity as an expression of the resistance of the culture to communism (Kundera, 1986, April 26, 33). In the face of the centralized Soviet administration, Central European countries wanted to defend its plural culture. I think, that this diagnosis can be applied to phenomenology in particular. Doing phenomenology in the communist period was for 
many people and researchers an expression of the resistance of philosophy to materialism and Marxism. In addition, phenomenology in Central and Eastern Europe was developed as a plural movement, without a clear centre, as Leuven in the West.

Today phenomenology in this part of the world is vital, though unexplored. Of course, many phenomenologists from Central and Eastern Europe participate in global exchange of ideas, and take part in international discussions. Indeed, the process of globalization made the phenomenological movement more unified than ever. However, there was no opportunity to show a unique character, and an original contribution of Central and Eastern European phenomenology to contemporary debates. In this context, the issue of the «Horizon. Studies in Phenomenology» seems to be a significant contribution to our understanding what phenomenology in this part of the world was, is, and can be in the future. I believe that the issue enables a reader to see the plurality of the phenomenological heritage, as well as further perspectives of phenomenology in Central and Eastern Europe.

The present issue of the «Horizon. Studies in Phenomenology» gathers articles originally presented at the International Conference on «Horizons Beyond Borders. Traditions and Perspectives of the Phenomenological Movement in Central and Eastern Europe» that held on June 17-19, 2015 at the Institute of Philosophy of the Research Centre for the Humanities of the Hungarian Academy of Sciences in Budapest, Hungary. As such, the collection is a joint achievement of the participants of the event. I - also in the name of Peter Andras Varga - am grateful for their efforts to present a broader horizon on the phenomenological movement in Central and Eastern Europe. I believe that all presented contributions show a rich and complex structure - both in historical and systematical aspects - of the phenomenological movement in this part of Europe. At the end, I would like to express my thanks to Natalia Artemenko, Editor-In-Chief of the «Horizon. Studies in Phenomenology». Her generous support and help made possible a publication of this - as it seems - important collection of essays.

\section{REFERENCES}

Embree, L. (Ed.). (1997). Encyclopedia of Phenomenology. Dordrecht: Kluwer.

Gubser, M. (2014). The Far Reaches. Phenomenology, Ethics, and Social Renewal in Central 
Europe. Stanford, CA: Stanford University Press.

Kundera, M. (1986, April 26). The tragedy of central Europe. The New York Review of Books, 33-38.

Merleau-Ponty, M. (2002). Phenomenology of Perception. London- New York, NY: Routledge.

Spiegelberg, H. (1975). Doing Phenomenology. Essays on and in Phenomenology. The Hague: Martinus Nijhoff.

Spiegelberg, H. (1999). The Phenomenological Movement. A Historical Introduction. Dordrecht: Kluwer. 